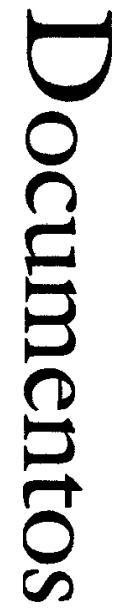




\section{A nova direção do IEA}

\section{UMBERTO G. CORDANI}

M agnífico Reitor, DD Membros do Conselho Universitário da USP, e demais autoridades presentes, colegas, amigos. De início desejo agradecer-lhe, Magnífico Reitor, pela demonstração de confiança ao escolher meu nome para dirigir o Instituto de Estudos Avançados. A responsabilidade é muito grande, e torna-se maior ainda se considerarmos a estatura dos dois Diretores que me antecederam, Carlos Guilherme Mota, e Jacques Marcovitch. Espero corresponder a esta confiança.

O Instituto de Estudos Avançados da USP é muito especial. De fato, no Estatuto da Universidade, ele está relacionado entre os institutos especializados, como o IEE, o IEB, o CENA, e o Cebimar. No

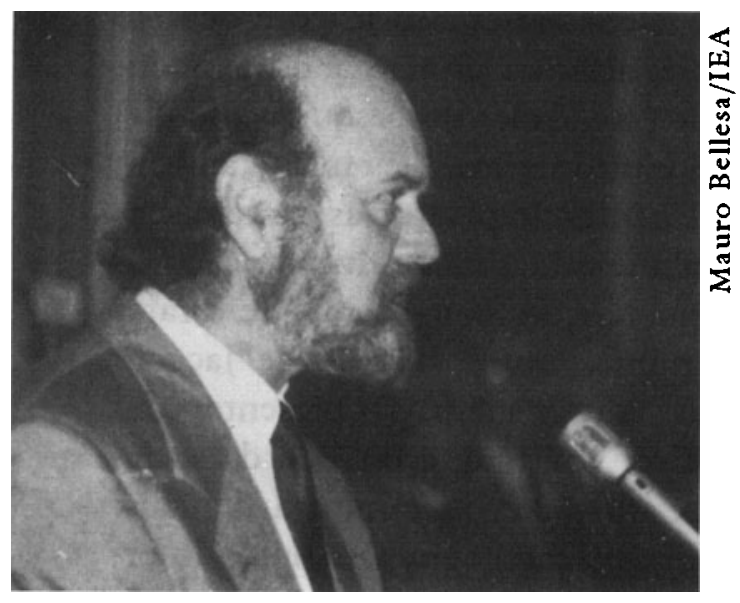

Umberto G. Cordani entanto, o IEA não possui alunos, o IEA não possui laboratórios de pesquisa, o IEA não possui um quadro de pesquisadores permanentes. De que se trata, entăo, e como se insere, na maior universidade brasileira, uma unidade sem alunos, sem laboratórios, sem pesquisadores?

O Instituto é muito recente, remontando sua criação a 1986. Vejo com satisfação que vários de seus idealizadores, inclusive alguns dos integrantes do primeiro grupo de estudos encarregado de seu planejamento, pelo então Reitor Goldenberg, encontram-se aqui presentes. Após analisar a estrutura e o funcionamento de unidades congêneres, como a de Princeton, de Berlim, de Paris, do México, e muitas outras, tal grupo de trabalho produziu um documento fundamental, sugerindo a criação de uma instituição de espírito aberto e ágil, integrada na comunidade uspeana e consciente de suas características e de sua história. Propôs que o novo instituto desse atenção a temas "de ponta" do pensamento contemporâneo, de preferência interdisciplinares, que se preocupasse com políticas de desenvol- 
vimento, visando uma melhor articulaçăo entre a Universidade e a sociedade, e que promovesse colaboração entre os pesquisadores da USP com personalidades da vida cultural, nacional e mundial. No regimento vigente, tais preceitos foram confirmados e descritos com os pormenores necessários, na delimitação da esfera de competência do Instituto.

Na proposta do seu novo regimento, o IEA é definido como órgão de integração da Universidade de São Paulo, e seus objetivos fundamentais são descritos como sendo os de estudar, pesquisar e discutir as questôes fundamentais da ciência e da cultura contemporâneas, de forma abrangente e interdisciplinar. Poderia haver maior abrangência? É viável buscar atingir tais objetivos, ou quem sabe apenas alguns deles? E quais seriam os mecanismos? Quais os caminhos?

Permitam-me citar aqui um pequeno trecho de um poema espanhol: Caminante, no bay camino, / el camino se bace al andar.

El camino se hace al andar. Em seus poucos anos de vida, o Instituto de Estudos Avançados da USP já construiu muitos caminhos, abriu muitos espaços. Seu primeiro Diretor, Carlos Guilherme Mota, em seus dois anos de gestão, implantou o IEA em seu espaço físico e deu-lhe uma estrutura administrativa. Como realizaçóes principais do período, Carlos Guilherme ensejou o início de atividades de pesquisa interdisciplinar em certos campos considerados prioritários. Deu início também aos programas com Pesquisadores Visitantes, implantou as conferências magistrais do Instituto, e deu origem à revista Estudos Apanfados, considerada hoje um modelo entre as publicaçóes congêneres, de caráter interdisciplinar. Nos cinco anos seguintes, sob a direçáo de Jacques Marcovitch, o IEA desenvolveu-se até atingir a situaçáo presente, com presença marcante no cenário científico, cultural, e político da sociedade nacional. No período, as áreas de atuação evoluíram para as atuais: Ciências Ambientais, Política Científica e Tecnológica, Assuntos Internacionais, Lógica e Teoria da Ciência, e História Cultural. Foram assinados dois importantes convênios com entidades externas para assegurar recursos a programas de estudo de interesse do Instituto: as chamadas Cátedras Jaime Cortesão e Simon Bolivar. Finalmente, foram desenvolvidos com grande sucesso alguns programas mobilizadores, para estabelecer respostas a problemas prioritários da sociedade brasileira, tais como o Projeto Floram, o Forum Capital-Trabalho, o Programa Educagáo para Cidadania e o Programa Revisáo Constitucional.

Durante o ano de 1993, o Instituto abrigou 13 Professores Visitantes, mas participaram de seus eventos cerca de 1300 docentes de quase todas as unidades da USP, mais de $\mathbf{5 0 0}$ professores e pesquisa- 
dores de entidades externas, nacionais e internacionais, bem como cerca de 300 elementos da vida pública nacional, políticos, empresários, e figuras representativas da sociedade civil. Estes poucos dados quantitativos dáo idéia do atual nível de atividades do IEA e, portanto, das responsabilidades que me esperam, a partir de agora. Considero como missão principal manter e eventualmente buscar expandir o que já foi desenvolvido. Além disso, gostaria de favorecer uma participaçáo maior do instituto em três níveis principais:

- de início, no plano interno da USP, entendo que existem inúmeros pesquisadores e grupos de pesquisa de vanguarda, em quase todas as unidades da Universidade, que elaboram estudos avançados e trabalham em aspectos de fronteira da ciência, mas que ainda não mantêm qualquer vínculo com o IEA. Năo se trata aqui do Instituto substituir-se às demais unidades da USP, mas apenas de favorecer, estimular, e divulgar adequadamente tais atividades de ponta, em eventos promovidos em colaboração, além de proporcionar os contatos externos, inclusive internacionais, que possam favorecer um desenvolvimento ulterior das pesquisas, e a busca de uma interdisciplinaridade eventualmente necessária e/ou desejável;

- no âmbito nacional, o Instituto já vem atuando de maneira expressiva, através de seus programas mobilizadores. Por outro lado, ao discutir as prioridades para o biênio 1994-95, o novo Conselho Diretor já indicou sua preferência por alguns aspectos importantes da problemática nacional, tais como a fome no país, a ocupaçáo dos espaços e o zoneamento da Amazônia, as possibilidades de previsão das secas no Nordeste e sua mitigação etc. Outro aspecto longamente debatido pelo Conselho do IEA foi o da inserção do país na economia mundial, tema que me leva para o item seguinte;

- com relaçáo ao plano internacional, considero importante a abordagem de assuntos ligados ao desenvolvimento sustentável. A Conferência das Naçóes Unidas sobre Ambiente e Desenvolvimento foi um marco na história da humanidade, ocasiáo em que a consciência mundial foi despertada para a necessidade de atingir, em poucas décadas, a situaçáo idealizada de desenvolvimento sócio-econômico mais ou menos equilibrado, em todo o globo, mantida a qualidade ambiental, e assegurada a integridade dos recursos naturais renováveis (água potável, alimentos, energia etc.). Por outro lado, se a consciência mundial foi despertada, as açóes decorrentes foram muito poucas, porque os que detêm o poder, no mundo inteiro, ainda têm muitas dúvidas a respeito dos mecanismos que se fazem 
necessários para favorecer situações de desenvolvimento sustentável. A economia mundial está cada vez mais integrada, repleta de interdependências; as ciências sociais são desafiadas a pensar o mundo não mais como uma somatória de sociedades regionais ou nacionais independentes, mas como uma sociedade global; os fenômenos naturais da dinâmica de nosso planeta são estudados cada vez mais de maneira integrada, (a Ciência do Sistema Terra), e o ambiente em que vivemos é encarado cada vez mais de maneira holística. Trata-se de grandes mudanças de escala, de enfoque, de mentalidade, e entendo que o Instituto tem um importante papel a exercer, no sentido de conduzir as reflexóes pertinentes.

Finalmente, numa unidade sem pessoal permanente, e com flexibilidade orçamentária pequena, mesmo que existam grandes planos e excelentes idéias, o diretor pouco poderá influir para a sua execução se não puder contar com a boa vontade e os esforços voluntários das unidades congêneres da USP, e de muitas instituiçōes externas à Universidade. Confio nesta colaboraçáo estreita, e desde já coloco-me a disposiçáo para examinar e discutir quaisquer proposiçóes de trabalhos conjuntos dentro dos objetivos do Instituto. Tenho a certeza de contar com a ajuda e a compreensão das altas autoridades da USP, em especial a Pró-Reitoria de Pesquisa, à qual está subordinado o IEA, e a Pró-Reitoria de Cultura e Extensão, visto que seu titular seguramente participará de muitos programas e eventos do Instituto.

Quanto ao Magnífico Reitor, em sua visita recente ao IEA já deixou muito claro o seu interesse pessoal em muitos dos tópicos abordados pelo Instituto. Esclareceu também que poderá propor, e mesmo encomendar ao Instituto, estudos e projetos que sejam de eventual interesse da própria Reitoria, do Conselho Universitário, enfim, da Universidade. Por outro lado, o IEA espera a participaçáo direta do Dr. Fava, na medida de suas possibilidades atuais, nas várias questóes em que ele puder contribuir com sua sabedoria e sua experiência, tal como ocorreu em muitas ocasiōes anteriores.

\section{Reitor, Senhores Conselheiros, Colegas,}

Acredito firmemente que a Ciência e a Universidade poderáo exercer um papel de extrema relevância nestas questóes que atualmente afligem a humanidade, na busca dos novos caminhos que conduzam a uma sociedade, não só auto-sustentável, mas também mais equilibrada, mais justa. Acredito no papel que a Universidade de Sáo Paulo poderá assumir, como uma das melhores, senão a melhor, do Terceiro Mundo, e acredito que nela poderá ser de grande importância o papel integrador, 
catalisador do Instituto de Estudos Avançados. Como diretor do IEA, espero poder contribuir para promover ou acelerar alguns desenvolvimentos neste sentido.

Umberto G. Cordani é diretor do Instituto de Estudos Avançados da USP, professor do Instituto de Geociências da USP, membro do Comitê TécnicoCientífico da Década Internacional de Reduçāo de Desastres Naturais da ONU c autor de mais de 180 publicaçóes científicas (artigos, capítulos de livros etc.) no Brasil e no exterior.

Discurso de posse para a diretoria do Instituto de Estudos Avançados da USP, feito pelo autor em 25 de fevereiro de 1994, no gabinete do reitor da Universidade de São Paulo, professor Flávio Fava de Moraes. 